\title{
Differential diagnoses of enamel hypomineralisation in an archaeological context: A post-medieval skeletal collection reassessment
}

Garot Elsa ${ }^{1,2,3 *}$, Couture-Veschambre Christine ${ }^{2}$, Manton David John ${ }^{4}$, Bekvalac Jelena ${ }^{5}$, Rouas Patrick ${ }^{1,2,6}$

${ }^{1}$ Univ. de Bordeaux, UFR des Sciences Odontologiques, Bordeaux, France

${ }^{2}$ Univ. de Bordeaux, PACEA UMR 5199, CNRS, MCC, Pessac, France

${ }^{3}$ Centre de Compétence des Maladies Rares Orales et Dentaires, CCMR O-Rares, C.H.U. de Bordeaux, France.

${ }^{4}$ Melbourne Dental School, University of Melbourne, Victoria, Australia

${ }^{5}$ Centre for Human Bioarchaeology, Museum of London, London, United Kingdom

${ }^{6}$ C.H.U de Bordeaux, Bordeaux, France

*corresponding author

elsa.garot@u-bordeaux.fr

UFR d'Odontologie Bordeaux - 146 rue Leo Saignat - CS 61292 - 33076 Bordeaux cedex

Declarations of interest: none

\begin{abstract}
Developmental enamel defects (DDE) are often used as indicators of general health in past archaeological populations. DDE include three common types of lesions: hypoplasia, diffuse and demarcated opacities. Molar Incisor Hypomineralisation (MIH) was defined in 2001 as a qualitative enamel defect affecting first permanent molars and often permanent incisors. The European Academy of Paediatric Dentistry (EAPD) established criteria to diagnose MIH in current populations as demarcated white or yellow-brown opacities of enamel with or without post-eruptive breakdown. $\mathrm{MIH}$ is prevalent in current populations (average 14.2\%) and may cause important damage to first permanent molars. Aetiological factors are uncertain. The discovery of MIH in archaeological skeletal collections based on macroscopic examination has been reported previously, in particular by Ogden and colleagues (2008). If MIH exists in past populations there are profound implications regarding current aetiological hypotheses. Aims of the present study were to: (1) reassess the London postmedieval archaeological collection from which the first cases of $\mathrm{MIH}$ were reported and evaluate the reliability of MIH diagnosis criteria in past populations, (2) differentially diagnose developmental defects of enamel and post-mortem discoloration in the teeth. Contrary to the reported prevalence in the original study (93.2\%), among 47 sub adults (>18

This is the author manuscript accepted for publication and has undergone full peer review but has not been through the copyediting, typesetting, pagination and proofreading process, which may lead to differences between this version and the Version of Record. Please cite this article as doi: 10.1002/oa.2785
\end{abstract}

This article is protected by copyright. All rights reserved. 
years) individuals a low MIH prevalence was determined (27\%). Reliability of MIH diagnosis was tested with three MIH experts who were also physical anthropologists. Our study highlighted that the reliability of a macroscopic diagnosis of MIH in past populations is fair (Cohen's kappa $=0.35 \pm 0.11$; Fleiss's kappa $=0.3$ ). It could explain the large differential in prevalence values in studies performed in archaeological collections. Pathological and taphonomic agents can produce enamel modifications indistinguishable from one another, even to an 'experienced eye'. Here, we examined the literature to highlight potential differential diagnoses of MIH (taphonomic discoloration, amelogenesis imperfecta, fluorosis, rachitic teeth etc.). Employing non-destructive analyses to characterise and diagnose tooth discoloration in past populations is highly recommended.

Running head: Developmental enamel hypomineralisation and taphonomic discoloration.

Keywords: archaeological; pathology; enamel; hypomineralisation 


\section{Introduction}

Tooth enamel develops in a defined period, involving ameloblasts, secretory cells that produce enamel, that are particularly sensitive to changes in their environment during amelogenesis (Suga 1989). Ameloblast dysfunction can occur, resulting in changes in enamel appearance. These developmental defects of enamel (DDE) may include slight abnormalities of tooth colour to a complete absence of enamel. One of the first reports on DDE appeared over 200 years ago when rickets, measles, and scurvy were associated with "erosion" of the teeth (Bunon 1743). Syphilis was later included as an aetiological factor (Suckling 1989). The Fédération Dentaire Internationale (FDI) index of developmental defects classified enamel lesions as hypoplasia, diffuse and demarcated opacities (International Dental Federation. Commission on Oral Health and Epidemiology 1982). Dental pathologies, such as enamel hypoplasia or caries, provide information on the nutritional status of a population or social status of an individual (Goodman et al. 1980; Walter et al. 2015). These dental pathologies should also include enamel hypomineralisation which is defined as an abnormality in the mineral density and translucency of the enamel (Jalevik and Noren 2000). The term Molar Incisor Hypomineralisation (MIH) was adopted by the scientific community in 2001 to describe a specific pattern of developmental demarcated enamel hypomineralisation in the first permanent molars, also commonly affecting permanent incisors (Weerheijm et al. 2001). However, it may be supposed that MIH was described in previous studies but defined by other terms as Mottled enamel (Black and McKay, 1916 cited by Smith (1916)), Developmental opacities (Hurme 1949), Idiopathic or nonfluoride opacities (Zimmermann 1954). In 1958, Bhussry described "opaque" demarcated enamel hypomineralisation (Bhussry 1958). Hypomineralised enamel and the characteristics of MIH were described specifically as a decrease in mineral density starting at the enamel-dentine junction towards the surface with a normo-mineralised surface (Crombie et al. 2013; Farah et al. 2010a; Farah et al. 2010b; Garot et al. 2016b). In hypomineralised enamel, even if, for example, the white defect the surface is sound, the hypomineralised enamel under the surface deviates and reflects the rays of the light, becoming imprisoned in an "optical maze" that is over-luminous and therefore perceived as white (Denis et al. 2013). 
The European Academy of Paediatric Dentistry (EAPD) established criteria in order to diagnose MIH in current populations. MIH is defined as white, yellow or brown demarcated opacities with or without post-eruptive enamel breakdown (Weerheijm et al. 2003). More recently, authors provided a comprehensive manual to assist researchers in planning epidemiological studies of MIH in current populations, with particular reference to outcome measurement (Ghanim et al. 2017). Nowadays, the MIH global prevalence varies, mean $13.1 \%$ (Schwendicke et al. 2018) and damage caused to functionally essential teeth make it a major public health problem (Schneider and Silva 2018). MIH may impact on the well-being of young patients in a crucial period of infant development (Dantas-Neta et al. 2016; Leal et al. 2017). Moreover, currently, in the absence of identified cause(s), no risk prevention actions can be implemented (Silva et al. 2016). In the past few decades modern life factors have been postulated as aetiological factors: environmental pollutants (Jedeon et al. 2013; Laisi et al. 2008); medications (Ghanim et al. 2013; Laisi et al. 2009; Serna et al. 2016; Whatling and Fearne 2008; Wogelius et al. 2010) or general factors: childhood disease (Silva et al. 2016; Tourino et al. 2016), hypoxia during birth (Garot et al. 2016a; Tourino et al. 2016), and a genetic predisposition (Jeremias et al. 2013; Kuhnisch et al. 2014; Vieira and Kup 2016) etc. However, aetiology of MIH is still unclear due to the multiplicity of causes and the nature of the majority of studies that are retrospective (Alaluusua 2010; Crombie et al. 2009). Recently, there has been research with a focus on MIH in past populations (Curzon et al. 2015; Garot et al. 2017a; Kuhnisch et al. 2016; Ogden et al. 2008). The presence of MIH in past populations is scientifically important as it could prioritise era-related aetiological factors without excluding the possibility of multifactorial aetiological factors. In 2008, Ogden and colleagues were the first to report MIH amongst an archaeological collection (Ogden et al. 2008). They studied a group of 45 individuals from a post-medieval collection excavated during the development of Broad Street and Liverpool Street underground stations in London. The skeletal remains revealed during the excavations in 1985 (LSS85) were of individuals buried in the Broadgate cemetery a municipal cemetery known as the 'New Churchyard' opened in 1569 and in use until the mid- $18^{\text {th }}$ century. The site was partially excavated from 1984 to 1987 by the Museum of London Department of Urban Archaeology. Not all of the skeletal remains revealed were retained for long-term research with several hundred skeletons 
reburied on site (Centre for Human Bioarchaelogy 2008). Amongst the 45 individuals examined it was reported in 2007 that 42 (93.2\%) had enamel hypoplasia (Ogden et al. 2007). However, one year later, the same authors reattributed all of the hypoplasia to MIH (Ogden et al. 2008) based on the MIH definition (Weerheijm 2003; Weerheijm et al. 2003). Since this first paper, MIH in ancient teeth based on visual examination has been reported by other authors (Curzon et al. 2015; Kuhnisch et al. 2016; Rouas 2012). However, in an archaeological context, the issue is more complicated and less certain as teeth and bones might be taphonomically stained yellow or brown by manganese or iron from the burial soil and processes affecting the burial environment (Turner-Walker 2007). Taphonomic staining of the dentition may have a similar appearance to enamel hypomineralisation (Garot et al. 2017b; McKay et al. 2013) and thus be a cause for misrepresenting the true prevalence of MIH within archaeological collections. Recently it was proposed that non-destructive analyses could be used to distinguish taphonomic stain and MIH in archaeological human skeletal remains (Garot et al. 2017b). Based on this guide, MIH on three individuals from French osteological collections were diagnosed (Garot et al. 2017a). With the individuals from the Broadgate collection study (LSS85), no distinction had been made between taphonomy and developmental pathology (Ogden et al. 2008). Moreover, the prevalence figure (93.2\%) deviated significantly from MIH prevalence in current populations (Elfrink et al. 2015). In order to account for post-mortem changes, examiners have to consider differential diagnoses of MIH. The authors have addressed this issue with developmental defects (without $\mathrm{MIH}$ ) and post-mortem changes in archaeological porcine teeth (Kierdorf et al. 2009), but no previous studies have created an inventory of differential diagnoses of MIH in human past populations.

In this present study, we aimed (1) to re-examine the original individuals from the postmedieval Broadgate collection (LSS85) where the first cases of possible MIH were reported and (2) to perform a review of the differential diagnoses of MIH in this archaeological population.

\section{Materials and Methods}




\subsection{Post-medieval $\left(\mathrm{C}^{\text {th }}{ }^{\text {th }}\right.$ and $\left.\mathrm{C} 8^{\text {th }}\right)$ skeletal collection}

The skeletal remains for the study came from post-medieval London cemeteries curated and stored at the Centre for Human Bioarchaeology (CHB, Museum of London, UK). The archaeological series used for illustration of differential diagnosis are presented in the supplementary materials (Data S1). The present study is based on individuals previously recorded from the post-medieval Broadgate human skeletal collection (LSS85) by Bill White, comprising of 150 analysed individuals on the Wellcome Osteological Research Database (WORD). Although the 'New Churchyard' was opened in order to relieve the congestion occurring in the existing parish churchyards, instead it became the burial place for the poorer members of London society. The 150 individuals were divided into two groups depending on age: the sub adult group (0-17 y) with 73 individuals and the adult group (> 18 y) with 77 individuals. To diagnose MIH, at least one first permanent molar (M1) had to be erupted. Because of the often prevalent early damage to the M1 due to dental caries, wear or antemortem loss, the adult group (>26 y) was excluded (Esclassan et al. 2009; Lucas et al. 2010; Novak 2015). Perinatal and those in the age category of 0-11 months were also excluded because the M1 crown is not fully developed whereas the 1-5 year group was included because some isolated M1 germs could be observed. A total of 65 individuals were included and examined (47 sub adults and 18 adults). Amongst the sub adult group ( $\mathrm{n}=47), 72$ M1 were observed and 22 individuals had at least one M1 erupted (Table 1). The reassessment and recording of the dentition of these 65 selected individuals was carried out at the CHB by E. Garot in 2015. The sub adults were unsexed and amongst the 6 adult individuals with at least one erupted M1, 5 were female and 1 male.

Table 1. Characteristics of sample.

\begin{tabular}{cc|cc|cccc}
\hline & $\begin{array}{c}\text { Selected } \\
\text { class }\end{array}$ & $\begin{array}{c}\text { Ind } \\
\text { examined }\end{array}$ & $\begin{array}{c}\text { M1 } \\
\text { observed }\end{array}$ & $\begin{array}{c}\text { Ind } \\
\text { with M1 }\end{array}$ & Male & Female & Unsexed \\
\hline \multirow{5}{*}{ Sub adult } & $1-5 \mathrm{y}$ & 16 & 16 & 5 & - & - & 5 \\
& $6-17 \mathrm{y}$ & 27 & 52 & 16 & - & - & 16 \\
& Unclassified & 4 & 4 & 1 & - & - & 1 \\
& Total & $\mathbf{4 7}$ & $\mathbf{7 2}$ & $\mathbf{2 2}$ & - & - & $\mathbf{2 2}$ \\
\hline Adult & $18-25 \mathrm{y}$ & $\mathbf{1 8}$ & $\mathbf{1 0}$ & $\mathbf{6}$ & $\mathbf{1}$ & $\mathbf{5}$ & - \\
\hline & Total & $\mathbf{6 5}$ & $\mathbf{8 2}$ & $\mathbf{2 8}$ & $\mathbf{1}$ & $\mathbf{5}$ & $\mathbf{2 2}$ \\
\hline
\end{tabular}


n, number; ind, individual; tot, total; M1, first permanent molar; Ind with M1, at least one M1 erupted.

\subsection{Dental examination}

The data recording and examination of the individuals was performed by one examiner (EG) at the CHB. The skeletal remains were archaeologically derived and identified through the site code and context number. The analysis of the individuals from Broadgate was conducted by Mr Bill White (deceased curator emeritus from the Museum of London). Age estimation for the sub adults was based on diaphyseal long bone measurements, epiphyseal fusion and dental development (Powers 2012). For the adults, estimation for biological sex and age were based upon the characteristics and traits of the skull and pelvis (Powers 2012). The current WORD data for the individuals recorded is available to download through the CHB website with dentition following the FDI method and dental pathology except for MIH (Centre for Human Bioarchaelogy 2008).

Among the group, the following parameters were assessed by one examiner for each M1 (Fig. $1)$ :

- Hypoplasia defined as quantitative defect of enamel (Clarkson 1992);

- Discoloration;

- Established carious lesion superior to stage 2 determined by the International Caries Detection and Assessment System (ICDAS) classification (ICDAS foundation);

- Ante-mortem loss, distinguished from the post-mortem loss by at least some remodelling of the alveolar bone and tooth socket after tooth loss (Meller et al. 2009).

The following parameters were recorded for each tooth with discoloration (Fig. 2):

- Coronal location (occlusal third / median third / cervical third);

- Lesion colour (white, yellow, brown) (Oliver et al. 2013);

- Surface affected (buccal, lingual, occlusal, mesial, distal);

- Breakdown of enamel (EAPD criteria) (Weerheijm et al. 2003);

- Number of stained lesions per tooth (n);

- Demarcated i.e. delimited edge (EAPD criteria; (Weerheijm et al. 2003)) or diffuse discoloration (Clarkson 1992).

This article is protected by copyright. All rights reserved. 


\subsection{Reliability and reproducibility}

Reproducibility and reliability of MIH and taphonomic diagnoses were tested with three examiners who are physical anthropologists and paediatric dentists with extensive knowledge of developmental defects of enamel. Preliminary intra- and inter-examiner error tests for the diagnosis of MIH with images of current teeth were performed between the three MIH experts (EG, PR, DM) who worked together previously identifying MIH. MIH diagnosis was based on EAPD criteria (Weerheijm et al. 2003). The scoring of MIH in a current population using a camera captured image was validated by a previous study among 649 children (intra, $\kappa=$ 0.85; inter, $\kappa=0.69$ ) (Elfrink et al. 2009). Our tests were carried out at fixed time intervals (two weeks) on nine photographed cases with different presentations of MIH and varied dental conditions (fluorosis, carious lesions, trauma-related hypomineralisation). The cases chosen were patients from teaching dental hospitals of Bordeaux and a private dental practice. Cases were randomly reordered for the second test. The test consisted of two questions to answer in each case: 1. Is it typical of MIH lesion? (Yes/No/Unsure); 2. How did you make your decision? (Open-ended question).

Concerning the individuals from the Broadgate collection, for each individual with enamel discoloration, photographs were taken by one examiner of the maxillae and mandible using a Nikon ${ }^{\circledR}$ (Japan) D90, a ring flash macro Metz ${ }^{\circledR}$ (Germany) and a lens Tamron ${ }^{\circledR}$ (Japan) SP AF $90 \mathrm{~mm} / 2,8$. Photographs (Data S2) were examined by the three investigators (EG, PR, DM). The test consisted of four questions to answer in each case: 1. Is it typical of an MIH lesion? (Yes/No/Unsure); 2. How did you make your decision? (Open-ended question); 3. Is it typical of a taphonomic discoloration? (Yes/No/Unsure); 4. How did you make your decision? (Open-ended question). Cases were reordered for the second test performed two weeks after the first test. Examiners were aware that the photographs were from archaeological sample.

\subsection{Statistical analysis}


In order to test the intra-examiner agreement, the non-parametric Cohen's kappa test was used to determine agreement between the responses of each examiner. A Fleiss kappa test was performed to evaluate the degree of agreement between the three examiners (inter-examiner). A non-parametric test (U Mann Whitney) comparing the opacity type (demarcated or diffuse) with the MIH and taphonomic diagnoses was performed. All statistical tests were performed using Microsoft ${ }^{\circledR}$ Office Excel (Microsoft, WA, USA) and $\mathrm{R}^{\odot}$ statistical software (R Core Team 2018).

\subsection{Ethics statement}

Agreement and consent by the Centre for Human Bioarchaeology (Museum of London) for data recording and photography publications was obtained in advance of the study. The excavation process of the Broadgate site followed all procedures for notification of disturbance to a burial site. There was no identifying biographical information associated with any of the individuals in the study and thus this research does not constitute any risk to living descendants. Patients gave their consents for photographs which were anonymised.

\section{Results}

\subsection{Preliminary tests}

An almost perfect agreement (0.81-0.99) was obtained for MIH diagnosis in a current population between the three examiners (Fleiss kappa $=0.9$ ). Intra-examiner tests performed with current patients recorded also an almost perfect agreement $(\mathrm{m}=0.81 \pm 0.13)$.

\subsection{Data distribution}

Among the 72 M1 observed from 47 sub adults, 26\% ( $\mathrm{n}=19)$ showed discolorations, 3\% ( $\mathrm{n}=$ 2) were affected by carious lesions and no ante-mortem loss was observed (Table 2). Among the adult group ( $\mathrm{n}=18), 10$ M1 belonging to 6 individuals were observed; of these M1, 30\% $(\mathrm{n}=3)$ had hypoplasia, 20\% $(\mathrm{n}=2)$ had discolorations, $10 \%(\mathrm{n}=1)$ had a carious lesion and $8 \mathrm{M} 1$ were lost ante-mortem.

Table 2. Number of first permanent molars according to recording criteria 


\begin{tabular}{cccccc}
\hline Criteria & $\begin{array}{c}\text { Hypoplasia } \\
\text { nM1 }\end{array}$ & $\begin{array}{c}\text { Discoloration } \\
\text { nM1 }\end{array}$ & $\begin{array}{c}\text { Caries } \\
\text { nM1 }\end{array}$ & $\begin{array}{c}\text { Normal } \\
\text { nM1 }\end{array}$ & $\begin{array}{c}\text { AML } \\
\text { nM1 }\end{array}$ \\
\hline Sub adult & $15 / 72(21 \%)$ & $19 / 72(26 \%)$ & $2 / 72(3 \%)$ & $42 / 72(58 \%)$ & 0 \\
Adult & $3 / 10(30 \%)$ & $2 / 10(20 \%)$ & $1 / 10(10 \%)$ & $4 / 10(40 \%)$ & 8 \\
\hline Total & $\mathbf{1 8 / 8 2 ( 2 2 \% )}$ & $\mathbf{2 1 / 8 2 ( 2 6 \% )}$ & $\mathbf{3 / 8 2}(\mathbf{4 \%})$ & $\mathbf{4 6 / 8 2}(\mathbf{5 7 \%})$ & $\mathbf{8}$ \\
\hline
\end{tabular}

$\mathrm{M} 1$, first permanent molar; $\geq 1 \mathrm{M} 1$, at least one M1 erupted; AML, ante-mortem loss; $\mathrm{n}$, number; ind, individual.

The 21 discoloured teeth, belonging to 9 individuals, had been selected and photographed (Data S2). Among the 21 M1 selected, 12 discolorations were diffuse and 9 were demarcated (Table 3). A Fleiss kappa (inter-examiners test) was performed between the three examiners for each individual showing discoloration. At the question “is it typical of MIH?" examiners completely agreed to exclude (Fleiss kappa $=1$ ) the diagnosis of MIH for 3 individuals (LSS85 648, 1497 and 1371). The examiners were in perfect agreement (Fleiss kappa = 1) confirming taphonomic discoloration diagnosis on two individuals (LSS85 648 and LSS85 1497). The negative MIH diagnosis ( $\mathrm{P}>0.05)$ and the positive taphonomy diagnosis were all diffuse discolorations $(\mathrm{P}=0.04)$. Concerning the other individuals, no agreement was found (Fleiss kappa

$<$

$0)$. 
Table 3. Characteristics of discoloration and Fleiss' kappa (inter-examiners test) performed between the three examiners for each individual from Broadgate collection

\begin{tabular}{|c|c|c|c|c|c|c|c|c|c|}
\hline $\begin{array}{l}\text { Context } \\
\text { number }\end{array}$ & group & Age stage & Other anomalies & $\begin{array}{l}\text { M1 } \\
\text { observed }\end{array}$ & $\begin{array}{l}\text { Discolorations } \\
\text { n (M1) }\end{array}$ & $\begin{array}{l}\text { Diffuse } \\
\text { n (M1) }\end{array}$ & $\begin{array}{l}\text { Demarcated } \\
\text { n (M1) }\end{array}$ & $\begin{array}{l}\text { Kappa } \\
\text { MIH? }\end{array}$ & $\begin{array}{l}\text { Kappa } \\
\text { TPH? }\end{array}$ \\
\hline 1338 & Sub adults & $1-5$ & Cribra orbitalia & $16,26,36,46$ & 2 & / & 2 & $<0$ & $<0$ \\
\hline 648 & Sub adults & $1-5$ & & $16,26,36,46$ & 4 & 4 & I & $1(-)$ & $1(+)$ \\
\hline 852 & Sub adults & $1-5$ & & $16,26,46$ & 1 & / & 1 & $<0$ & $<0$ \\
\hline 1497 & Sub adults & $12-17$ & Cribra orbitalia & $16,26,36,46$ & 4 & 4 & l & $1(-)$ & $1(+)$ \\
\hline 684 & Sub adults & $6-11$ & & $16,26,36,46$ & 4 & I & 4 & $<0$ & $<0$ \\
\hline 1322 & Adults & $18-25$ & & $16,26,36,46$ & 2 & 2 & I & $<0$ & $<0$ \\
\hline 1487 & Sub adults & $6-11$ & Cribra orbitalia & $16,26,36,46$ & 1 & / & 1 & $<0$ & $<0$ \\
\hline 1197 & Sub adults & $6-11$ & & 16,36 & 2 & 1 & 1 & $<0$ & $<0$ \\
\hline 1371 & Sub adults & $6-11$ & & 26,46 & 1 & 1 & 1 & $1(-)$ & $<0$ \\
\hline Total & & & & 31 & 21 & 12 & 9 & 0.3 & 0.05 \\
\hline
\end{tabular}

n, number; M1, first permanent molar; TPH, taphonomic discoloration; <0, agreement less than chance; 1, perfect agreement; (-), negative responses; (+), positive responses. 
The results of intra-examiner tests are provided in Table 4. Among the Broadgate collection, scores of the third examiner (E3) are higher than the others (range 0.47 to 0.78 ). The means of Cohen's kappa indicated a fair agreement for each diagnosis of MIH and taphonomic discoloration and a moderate agreement for both diagnoses.

Table 4. Intra-examiner tests (Cohen's kappa) for each diagnosis in Broadgate (LSS85) collection

\begin{tabular}{lllllll}
\hline Site code & Kappa & E1 & E2 & E3 & $\mathrm{m} \pm$ SD & Agreement Interpretation $(\mathrm{m})$ \\
\hline LSS85 & MIH & 0.265 & 0.32 & 0.47 & $0.35 \pm 0.11$ & fair $(0.21-0.40)$ \\
& TPH & -0.18 & 0.04 & 0.79 & $0.22 \pm 0.51$ & fair $(0.21-0.40)$ \\
& MIH + TPH & 0.27 & 0.22 & 0.78 & $0.42 \pm 0.31$ & moderate $(0.41-0.60)$ \\
\hline
\end{tabular}

E, examiner; m, mean; SD, standard deviation; TPH, taphonomic discoloration; $\mathrm{MIH}+\mathrm{TPH}$, both diagnoses.

After excluding the 3 individuals (LSS85 648, LSS85 1497 and LSS85 1371) who were identified as not MIH (Fleiss kappa = 1), distributions and characteristics of discolorations were recorded (Fig. 3). Maxillary M1 (n=7) were more represented than mandibular M1 (n= 5). No discolorations were white, they were yellow or brown. Most of the discolorations were distributed between the occlusal and buccal surfaces. All the discolorations were in the occlusal third.

\section{Discussion}

\subsection{Post-medieval skeletal collection reassessment}

In the present study, the re-examined individuals came from the Broadgate cemetery and were previously examined by Ogden and colleagues (Ogden et al. 2007; Ogden et al. 2008). These authors reported a MIH prevalence of $93.2 \%$. In the present study, considering only the sub adult group $(n=47)$ with at least one M1 present $(n=22)$, only six had discolorations on M1 but without any certainty that they were representative of MIH. Even though we attributed these unknown discolorations to $\mathrm{MIH}$, a far lower prevalence was determined (27\%). Several reasons could explain these differences. First, MIH is often employed to describe "enamel developmental dysplasia" by the original authors (Ogden et al. 2008). Dysplasia may be a quantitative defect of enamel as is hypoplasia (Ruch 2001). Somewhat confusingly, in a 
previous study the same authors published a study including the same sub adult individuals and diagnosed 93.2\% of individuals with enamel hypoplasia (Ogden et al. 2007). Moreover, some defects in primary molars were attributed to MIH outside the definition which includes only hypomineralisation of permanent first molar and incisor teeth. Hypomineralised lesions on second primary molars have been described in current populations as Hypomineralised Second Primary Molars (HSPM) (Elfrink et al. 2008). HSPM is considered as a predictive factor for MIH (Elfrink et al. 2015; Mittal and Sharma 2015; Negre-Barber et al. 2016). Contrary to the high figure of $93.2 \%$ of MIH previously reported in the Broadgate collection (Ogden et al. 2008), Kühnisch and colleagues reported a MIH prevalence of $3.1 \%$ among three archaeological collections from late medieval $\left(n=191,12^{\text {th }}-16^{\text {th }}\right.$ century, Regensburg, Germany), post-medieval ( $\mathrm{n}=33,16^{\text {th }}-18^{\text {th }}$ century, Passau, Germany) and modern age archaeological skeletal series $\left(\mathrm{n}=99,19^{\text {th }}-20^{\text {th }}\right.$ century, Altdorf, Germany) (Kuhnisch et al. 2016). It is reasonable to assume that due to high prevalence of dental caries, ante-mortem loss, calculus and tooth wear on M1 (Esclassan et al. 2009; Lucas et al. 2010; Novak 2015; Vodanovic et al. 2005) and the greater proportion of adults from 21 to more than 60 years-ofage $(91 \% ; 305 / 336$ subjects), the prevalence could be underestimated (Kuhnisch et al. 2016). A systematic review highlighted a significant association between $\mathrm{MIH}$ and caries (Americano et al. 2017) in current populations. These carious lesions could destroy hypomineralised lesions or be the causative factor of ante-mortem loss. Among the present sample of 6 young adults, 8 had ante-mortem loss of the first permanent molar, which contrasted with the immature group $(n=45)$ where no ante-mortem loss of the first permanent molars was recorded.

The inter-examiner tests highlighted that MIH diagnosis in current populations is reliable $($ Fleiss kappa $=0.9)$ contrary to that amongst an archaeological collection (Fleiss kappa $=$ 0.3). In Kühnisch's study, diagnosis of MIH is based on EAPD criteria established in 2003 i.e. the presence of a demarcated opacity on at least one first permanent molar (Kuhnisch et al. 2016; Weerheijm et al. 2003). The unambiguous presence of a demarcated discoloration served as a main diagnosis indicator to record a surface affected by MIH (Kuhnisch et al. 2016). However, in the present study the EAPD criteria do not seem to be sufficiently reliable 
to assign a MIH diagnosis in historical teeth. MIH diagnosis can be subject to many biases in archaeological teeth including taphonomic processes and enamel anomalies making a differential diagnosis of MIH (Garot et al. 2017a).

\subsection{Differential diagnosis of MIH in archaeological skeletal remains}

Recently, in current population studies authors listed MIH differential diagnosis as: fluorosis, enamel hypoplasia, amelogenesis imperfecta and white spot lesion (Ghanim et al. 2017). In archaeological collections, burial conditions involve other discolorations looking like MIH.

\subsubsection{Taphonomic discolorations}

Changes in skeletal remains resulting from their interaction with the soil environment and microorganisms have an impact on almost all aspects of a palaeopathological study. The term "taphonomy" was originally defined by palaeontologist I.A. Efremov in 1940 as "the study of the transition of animal remains from the biosphere into the lithosphere" (Efremov 1940). Increased mineral content (manganese, iron or copper) from burial soil in teeth or bone causes discoloration (Garot et al. 2017b; McKay et al. 2013; Stermer et al. 1996; Stipisic et al. 2014). Examples of different types of taphonomic staining on teeth are shown in Fig. 4; following EAPD criteria, this kind of well demarcated discoloration on first permanent molars would be attributed to MIH, a misdiagnosis. Presence of stain on adjacent teeth confirmed the misdiagnosis. In the present study, two criteria to diagnose taphonomic discolorations were cited by the three examiners: (i) immaturity of M1 (case 2) - porosity increased incorporation of chemical elements from the soil and (ii) presence of discolorations on adjacent teeth (case 4). However, it cannot be excluded that a M1 could be affected by both hypomineralisation and taphonomic processes. Due to the porosity of hypomineralised enamel, the presence of MIH makes a tooth more susceptible to the processes of taphonomy.

\subsubsection{Intrinsic defects}

Enamel hypoplasia is one of the most frequently recorded developmental abnormalities of the human dentition ( $\mathrm{Li}$ et al. 1995). This quantitative defect is indicative of a disturbance of the secretory stage of enamel. Clinically the defect is visually and morphologically identified by 
various irregularities of enamel thickness such as pits, grooves or absence of enamel structure, over the tooth surfaces (Fig. 5a) (FDI 1982).

Amelogenesis imperfecta (AI) is a rare hereditary genetic disease. Hypomature and hypomineralised AI cause defects similar to MIH. The AI affects all the teeth of the individual which makes it possible to differentiate it from the MIH which only affects the first permanent molars and possibly the permanent incisors (Crawford et al. 2007).

Dental fluorosis is a qualitative abnormality of enamel due to excessive fluoride ingestion during tooth mineralisation. Fluoride could be disseminated into water, food or medication. Drinking water containing fluoride naturally or by addition for caries prevention varies among geographic areas. Contrary to $\mathrm{MIH}$, the lesions are diffuse and symmetrical and can affect all teeth. Discolorations can be white to brown (Abanto Alvarez et al. 2009; Aoba and Fejerskov 2002; Ruch 2001).

Hypomineralisation of traumatic origin also called "Turner's tooth" occurs during an insult to the primary tooth which will disrupt amelogenesis of the succedaneous tooth (Brin et al. 1984; Da Silva Assunção et al. 2009). Hypomineralisation arises when the trauma occurs during the maturation phase of the permanent tooth, it may be accompanied by hypoplasia when it occurs earlier in the amelogenesis (Denis et al. 2013). This type of hypomineralisation cannot be observed on first permanent molars due to the absence of predecessor tooth.

Congenital syphilis is an infectious disease belonging to the group of treponematoses caused by the spirochetal bacterium Treponema pallidum. It can be transmitted through sexual contact or transmitted transplacentally to the developing foetus by an infected mother (Ortner 2003). This disease is characterised by quantitative abnormalities (hypoplasia) of the enamel (Fig. 5b) (Lauc et al. 2015). Some signs are pathognomonic of this disease as mulberry molar and Hutchinson incisor (Ortner 2003). Treponemal infection of enamel organs damages or destroys the ameloblasts and disrupts the formation of tooth germs (Bauer 1944; Hillson et al. 1998). Disturbances in amelogenesis due to congenital syphilis mostly appear around birth 
and decrease throughout time. This locates enamel defects on the first molars and permanent incisors whose crown mineralization starts around birth (Lauc et al. 2015).

The early stages of carious lesions named "white spot lesions" are observable as white patches on the tooth surface where dental plaque accumulates (Fig. 5c). The imbalance of demineralisation / remineralisation by decrease of $\mathrm{pH}$ induces a crystalline dissolution along the prisms and Retzius lines (Denis et al. 2013). However, carious lesions are located in the most vulnerable areas (cervical third, interproximal contact point and occlusal pit and fissures) (Lanfranco and Eggers 2010; Stránská et al. 2015). MIH is more frequently present on the cusps and buccal surfaces of the tooth (Oyedele et al. 2015; Petrou et al. 2015). In $\mathrm{MIH}$-affected teeth, the cervical third of the enamel always has a normal appearance (Jalevik and Noren 2000).

Individuals' dentition affected with rickets resulting from a vitamin D deficiency are characterised by hypomineralisation of dentine and enamel, but also enamel hypoplasia and periodontal damage (D'Ortenzio et al. 2016; Foster et al. 2014; Koehne et al. 2012). In Fig. 5 (e-g), individual OCUOO $230\left(18^{\text {th }}-19^{\text {th }}\right.$ century, Chelsea Old Church, Museum of London) showed signs of "rickets" with enamel hypoplasia and hypomineralisation on incisors, canines and molars, periodontal lesions on permanent molars and a narrow maxilla. Other indications associated to "rickets" were recorded by J Bekvalac and T Kausmally on the WORD "Healed rickets of the lower limbs. Both femora on the anterior surface at the proximal end had a slight crest \& bulging on the lateral aspect of the shaft. The tibiae appeared to be most affected at the proximal end \& bulged towards the medial aspect. No changes were seen in the sternal rib ends and the build up of new bone on the shafts would suggest healing." (Centre for Human Bioarchaelogy 2008).

\subsubsection{Extrinsic discoloration}

Extrinsic discoloration is the result of pigment deposited on the surface of the tooth. Over time the teeth become discoloured due to exposure to substances such as tobacco, betel nut, coffee and tea. Extrinsic colorations can also be associated with occupational exposure to 
metal salts and with a number of drugs containing metal salts. Black dental staining is characteristic in people using iron supplements and workers in iron smelting. A number of other metals have been associated with dental discoloration such as copper (green discoloration), potassium permanganate (violet discoloration), silver nitrate salt (grey discoloration) and tin fluoride (brown discoloration) (Watts and Addy 2001). These factors could also be observed in the teeth of people from archaeological contexts so the time parameters and context of the sites should be considered.

\subsubsection{Intrinsic discoloration}

Intrinsic discoloration includes developmental defects mentioned above, to which is added ante or post-mortem extrinsic contamination. The porous surface of these defects (i.e. amelogenesis imperfecta or fluorosis) will more readily incorporate substances of extrinsic origin. These discolorations also comprised acquired defects, for example, white spots (first step of decay) incorporating taphonomic or mimicking extrinsic agents MIH (Fig. 5d).

\subsection{Methodological considerations}

Previous authors recommended using non-destructive detection/quantification methods highlighting mineral density decrease, as is the case in hypomineralised enamel and evidence of contamination by burial soil such as manganese or iron concentrations (Garot et al. 2017a; Garot et al. 2017b). To diagnose cases of MIH on archaeological teeth these analyses are greatly recommended. Comparing current and past prevalence of MIH will allow a better understanding of aetiological factors, the individuals, the environment and time in which they lived and died. Researchers agree that the aetiology is most likely multifactorial and occurs between the third trimester of pregnancy and the child's first year of life due to the mineralisation period of the first permanent molar (Alaluusua 2010; Crombie et al. 2009; Jeremias et al. 2013). Several dozen hypotheses have been cited, some are contemporary (e.g. antibiotics (Ghanim et al. 2013; Laisi et al. 2009; Serna et al. 2016; Whatling and Fearne 2008; Wogelius et al. 2010) or environmental pollutants (Jedeon et al. 2013; Laisi et al. 2008)), others have existed through time (e.g. peripartum problems (Garot et al. 2016a; Tourino et al. 2016), episodes of fever or childhood diseases (Silva et al. 2016; Tourino et al. 
2016)) without excluding a genetic predisposition (Jeremias et al. 2013; Kuhnisch et al. 2014; Vieira and Kup 2016).

Taking these assumptions into account, differences in the prevalence of MIH between distinct groups of individuals could also reflect inequalities in health status between the sexes or social categories. A high prevalence of MIH in an archaeological collection could be a sign of a precarious health condition in connection with difficulties during delivery, nutritional deficiencies or infections occurring during the first year of life of the child. An important point to highlight in the present study is that we investigated children who died before the age of 18 years, suggesting poor health linked to a mortality crisis. The causal factor of MIH occurs during the mineralisation period of the first permanent molar (Weerheijm et al. 2001). We can assume that a group of children raised in an unfavourable health context would have a higher prevalence of MIH than the overall population. Conversely, the examination of a group of adults leads to an underestimation of the prevalence of MIH due to dental caries, tooth wear or ante-mortem loss destroying these teeth. So, the type of study that would include the least bias in estimating the prevalence of MIH would focus on examining a large number of children aged 6-18 who died as a result of a fierce and non-selective killing event, a "Mortality crisis" (e.g. massacre, natural disaster or epidemic) affecting individuals of both sexes, of all ages and all health contexts (Blaizot and Castex 2005).

Considering the cost implications and availability when dealing with archaeological collections, the prevalence studies should consider some precautionary principles to reduce the number of individuals potentially affected by MIH to analyse:

- Inclusion of young individuals (8-10 y) as recommended in MIH prevalence studies in current populations (Elfrink et al. 2015).

- Exclusion of individuals showing discolorations in all of the dentition

- Exclusion of individuals with only germs of M1

- Study of individuals who died of an non-selective mortality crisis 
- Consideration of the individuals for the time period and place they were buried to aid as an indicator for the environment they were in and health factors of the time and location.

\section{Conclusions}

The present study highlights the potential hazards related to diagnosing $\mathrm{MIH}$ in past populations without enlisting the help of non-destructive analytical methods. This difficulty in accurate diagnosis due to taphonomic biases and MIH differential diagnosis (e.g. syphilitic teeth, amelogenesis imperfecta) could explain the big discrepancy in prevalence data reported from archaeological collections. Despite the small sample size, the present study provides new information on MIH in past populations. Notably the differential diagnosis of this anomaly, and the re-assessment of the individuals from the first "MIH in the past" publication allows a better understanding of disparities between previous MIH data. In future studies, some precautionary principles should be considered and microanalysis of affected teeth is recommended.

\section{Acknowledgements}

The authors are grateful to Jelena Bekvalac and Rebecca Redfern at the Centre for Human Bioarchaeology, Museum of London for providing access to the skeletal collection used in this study and for generously providing the physical facilities for this work.

\section{Supporting Information}

Data S1. The archaeological series St Mary Graces "MIN86" and Guildhall Yard "GYE92".

Data S2. Photographs of the 9 individuals with discoloration studied by the three examiners from Broadgate collection.

\section{Funding}

This work was supported by the Institut Français de Recherche Odontologique (IFRO) and the PRC CNRS-University of Melbourne (N501911 GL). 


\section{Authors' contributions}

Conceived and designed the experiments: EG, CCV, PR, DJM . Performed the experiments: EG, PR, DJM. Analysed data: EG, PR, CCV, JB, DJM. Wrote the paper: EG, CCV, PR, JB, DJM. 


\section{References}

Abanto Alvarez J, Rezende KM, Marocho SM, Alves FB, Celiberti P, and Ciamponi AL. 2009. Dental fluorosis: exposure, prevention and management. Medicina Oral, Patologia Oral y Cirugia bucal 14, 2:103-107.

Alaluusua S. 2010. Aetiology of Molar-Incisor Hypomineralisation: A systematic review. European Archives of Paediatric Dentistry 11, 2:53-58.

Americano GC, Jacobsen PE, Soviero VM, and Haubek D. 2017. A systematic review on the association between molar incisor hypomineralization and dental caries. International Journal of Paediatric Dentistry 27, 1:11-21.

Aoba T, and Fejerskov O. 2002. Dental fluorosis: chemistry and biology. Critical Reviews in Oral Biology and Medicine 13, 2:155-170.

Bauer WH. 1944. Tooth Buds and Jaws in Patients with Congenital Syphilis: Correlation between Distribution of Treponema pallidum and Tissue Reaction. The American Journal of Pathology 20, 2:297-319.

Bhussry BR. 1958. Chemical and physical studies of enamel from human teeth. III. Specific gravity, nitrogen content, and histologic characteristics of opaque white enamel. Journal of Dental Research 37, 6:1054-1059.

Blaizot F, and Castex D. 2005. Du bon usage des outils anthropologiques à l'étude des sociétés historiques. In: Dutour O, Hublin JJ, and Vandermeersch B, editors. Origine et évolution des populations humaines: Comité des travaux historiques et scientifiques. $\mathrm{p}$ 259-279.

Brin I, Fuks A, Ben-Bassat Y, and Zilberman Y. 1984. Trauma to the primary incisors and its effect on the permanent successors. Pediatric Dentistry 6, 2:78-82.

Bunon R. 1743. Essay sur les maladies des dents.: chez Briasson, Chaubert, et De Hansy.

Centre for Human Bioarchaelogy. 2008. Osteological database.

Clarkson J. 1992. A review of the developmental defects of enamel index (DDE Index). Commission on Oral Health, Research \& Epidemiology. Report of an FDI Working Group. International Dental Journal 42, 6:411-426.

Crawford PJ, Aldred M, and Bloch-Zupan A. 2007. Amelogenesis imperfecta. Orphanet Journal of Rare Diseases 2:17.

Crombie F, Manton D, and Kilpatrick N. 2009. Aetiology of molar-incisor hypomineralization: a critical review. International Journal of Paediatric Dentistry 19, 2:73-83.

Crombie FA, Manton DJ, Palamara JE, Zalizniak I, Cochrane NJ, and Reynolds EC. 2013. Characterisation of developmentally hypomineralised human enamel. Journal of Dentistry 41, 7:611-618.

Curzon ME, Ogden AR, Williams-Ward M, and Cleaton-Jones PE. 2015. Case report: A medieval case of molar-incisor-hypomineralisation. British Dental Journal 219, 12:583587.

D'Ortenzio L, Ribot I, Raguin E, Schattmann A, Bertrand B, Kahlon B, and Brickley M. 2016. The rachitic tooth: A histological examination. Journal of Archaeological Science 74:152-163. 
Da Silva Assunção LR, Ferelle A, Iwakura MLH, and Cunha RF. 2009. Effects on permanent teeth after luxation injuries to the primary predecessors: a study in children assisted at an emergency service. Dental Traumatology 25, 2:165-170.

Dantas-Neta NB, Moura LF, Cruz PF, Moura MS, Paiva SM, Martins CC, and Lima MD. 2016. Impact of molar-incisor hypomineralization on oral health-related quality of life in schoolchildren. Brazilian Oral Research 30, 1:e117.

Denis M, Atlan A, Vennat E, Tirlet G, and Attal JP. 2013. White defects on enamel: diagnosis and anatomopathology: two essential factors for proper treatment (part 1). International Orthodontics 11, 2:139-165.

Efremov I. 1940. Taphonomy, a new branch of paleontology. Biology Series 3:405-413.

Elfrink ME, Schuller AA, Weerheijm KL, and Veerkamp JS. 2008. Hypomineralized second primary molars: prevalence data in Dutch 5-year-olds. Caries Research 42, 4:282-285.

Elfrink ME, Veerkamp JS, Aartman IH, Moll HA, and Ten Cate JM. 2009. Validity of scoring caries and primary molar hypomineralization $(\mathrm{DMH})$ on intraoral photographs. European Archives of Paediatric Dentistry 10 Suppl 1:5-10.

Elfrink MEC, Ghanim A, Manton DJ, and Weerheijm KL. 2015. Standardised studies on Molar Incisor Hypomineralisation (MIH) and Hypomineralised Second Primary Molars (HSPM): a need. European Archives of Paediatric Dentistry 16, 3:247-255.

Esclassan R, Grimoud AM, Ruas MP, Donat R, Sevin A, Astie F, Lucas S, and Crubezy E. 2009. Dental caries, tooth wear and diet in an adult medieval (12th-14th century) population from mediterranean France. Archives of Oral Biology 54, 3:287-297.

Farah R, Drummond B, Swain M, and Williams S. 2010a. Linking the clinical presentation of molar-incisor hypomineralisation to its mineral density. International Journal of Paediatric Dentistry 20, 5:353-360.

Farah RA, Swain MV, Drummond BK, Cook R, and Atieh M. 2010b. Mineral density of hypomineralised enamel. Journal of Dentistry 38, 1:50-58.

FDI. 1982. Commission on Oral Health, Research and Epidemiology. An epidemiological index of developmental defects of dental enamel (DDE Index). International Dental Journal 32, 2:159-167.

Foster BL, Nociti FH, Jr., and Somerman MJ. 2014. The rachitic tooth. Endocrine Reviews 35, 1:1-34.

Garot E, Couture-Veschambre C, Manton D, Beauval C, and Rouas P. 2017a. Analytical evidence of enamel hypomineralisation on permanent and primary molars amongst past populations. Scientific Reports 7, 1:1712.

Garot E, Couture-Veschambre C, Manton D, Rodriguez V, Lefrais Y, and Rouas P. 2017b. Diagnostic guide enabling distinction between taphonomic stains and enamel hypomineralisation in an archaeological context. Archives of Oral Biology 74:28-36.

Garot E, Manton D, and Rouas P. 2016a. Peripartum events and molar-incisor hypomineralisation (MIH) amongst young patients in southwest France. European Archives of Paediatric Dentistry 4, 17:245-250.

Garot E, Rouas P, d'Incau E, Lenoir N, Manton D, and Couture C. 2016b. Mineral density of hypomineralised and sound enamel. Bulletin du Groupement International pour la Recherche Scientifique en Stomatologie \& Odontologie 53, 1:26-29. 
Ghanim A, Manton D, Bailey D, Marino R, and Morgan M. 2013. Risk factors in the occurrence of molar-incisor hypomineralization amongst a group of Iraqi children. International Journal of Paediatric Dentistry 23, 3:197-206.

Ghanim A, Silva MJ, Elfrink MEC, Lygidakis NA, Mariño RJ, Weerheijm KL, and Manton DJ. 2017. Molar incisor hypomineralisation (MIH) training manual for clinical field surveys and practice. European Archives of Paediatric Dentistry 18, 4:225-242.

Goodman AH, Armelagos GJ, and Rose JC. 1980. Enamel hypoplasias as indicators of stress in three prehistoric populations from Illinois. Human Biology 52, 3:515-528.

Hillson S, Grigson C, and Bond S. 1998. Dental defects of congenital syphilis. American Journal of Physical Anthropology 107, 1:25-40.

Hurme VO. 1949. Developmental opacities of teeth in a New England community; their relation to fluorine toxicosis. American Journal of Diseases of Children 77, 1:61-75.

ICDAS foundation. International Caries Detection and Assessment System. https://www.icdas.org/home.

International Dental Federation. Commission on Oral Health R, and Epidemiology. 1982. An epidemiological index of developmental defects of dental enamel (DDE index): FDI.

Jalevik B, and Noren JG. 2000. Enamel hypomineralization of permanent first molars: a morphological study and survey of possible aetiological factors. International Journal of Paediatric Dentistry 10, 4:278-289.

Jedeon K, De la Dure-Molla M, Brookes SJ, Loiodice S, Marciano C, Kirkham J, CanivencLavier MC, Boudalia S, Berges R, Harada H et al. . 2013. Enamel defects reflect perinatal exposure to bisphenol A. The American Journal of Pathology 183, 1:108-118.

Jeremias F, Koruyucu M, Kuchler EC, Bayram M, Tuna EB, Deeley K, Pierri RA, Souza JF, Fragelli CM, Paschoal MA et al. . 2013. Genes expressed in dental enamel development are associated with molar-incisor hypomineralization. Archives of Oral Biology 58, 10:1434-1442.

Kierdorf H, Kierdorf U, Witzel C, Intoh M, and Dobney K. 2009. Developmental defects and postmortem changes in archaeological pig teeth from Fais Island, Micronesia. Journal of Archaeological Science 36, 7:1637-1646.

Koehne T, Marshall RP, Jeschke A, Kahl-Nieke B, Schinke T, and Amling M. 2012. Osteopetrosis, osteopetrorickets and hypophosphatemic rickets differentially affect dentin and enamel mineralization. Bone.

Kuhnisch J, Lauenstein A, Pitchika V, McGlynn G, Staskiewicz A, Hickel R, and Grupe G. 2016. Was molar incisor hypomineralisation (MIH) present in archaeological case series? Clinical Oral Investigations 9, 20:1-7.

Kuhnisch J, Thiering E, Heitmuller D, Tiesler CM, Grallert H, Heinrich-Weltzien R, Hickel R, Heinrich J, Group G-PS, and Group LI-PS. 2014. Genome-wide association study (GWAS) for molar-incisor hypomineralization (MIH). Clinical Oral Investigations 18, 2:677-682.

Laisi S, Ess A, Sahlberg C, Arvio P, Lukinmaa PL, and Alaluusua S. 2009. Amoxicillin may cause molar incisor hypomineralization. Journal of Dental Research 88, 2:132-136.

Laisi S, Kiviranta H, Lukinmaa PL, Vartiainen T, and Alaluusua S. 2008. Molar-incisorhypomineralisation and dioxins: new findings. European Archives of Paediatric Dentistry 9, 4:224-227. 
Lanfranco LP, and Eggers S. 2010. The usefulness of caries frequency, depth, and location in determining cariogenicity and past subsistence: A test on early and later agriculturalists from the Peruvian coast. American Journal of Physical Anrthopology 143, 1:75-91.

Lauc T, Fornai C, Premuzic Z, Vodanovic M, Weber GW, Masic B, and Rajic Sikanjic P. 2015. Dental stigmata and enamel thickness in a probable case of congenital syphilis from XVI century Croatia. Archives of Oral Biology 60, 10:1554-1564.

Leal SC, Oliveira TR, and Ribeiro AP. 2017. Do parents and children perceive molar-incisor hypomineralization as an oral health problem? International Journal of Paediatric Dentistry 27, 5:372-379.

Li Y, Navia JM, and Bian JY. 1995. Prevalence and distribution of developmental enamel defects in primary dentition of Chinese children 3-5 years old. Community Dentistry and Oral Epidemiology 23, 2:72-79.

Lucas S, Sevin A, Passarius O, Esclassan R, Crubezy E, and Grimoud AM. 2010. Study of dental caries and periapical lesions in a mediaeval population of the southwest France: Differences in visual and radiographic inspections. HOMO-Journal of Comparative Human Biology 61, 5:359-372.

McKay S, Farah R, Broadbent JM, Tayles N, and Halcrow SE. 2013. Is it health or the burial environment: differentiating between hypomineralised and post-mortem stained enamel in an archaeological context. PloS One 8, 5:e64573.

Meller C, Urzua I, Moncada G, and von Ohle C. 2009. Prevalence of oral pathologic findings in an ancient pre-Columbian archeological site in the Atacama Desert. Oral Diseases 15, 4:287-294.

Mittal N, and Sharma BB. 2015. Hypomineralised second primary molars: prevalence, defect characteristics and possible association with Molar Incisor Hypomineralisation in Indian children. European Archives of Paediatric Dentistry 16, 6:441-447.

Negre-Barber A, Montiel-Company JM, Boronat-Catala M, Catala-Pizarro M, and AlmerichSilla JM. 2016. Hypomineralized Second Primary Molars as Predictor of Molar Incisor Hypomineralization. Scientific Reports 6:31929.

Novak M. 2015. Dental health and diet in early medieval Ireland. Archives of Oral Biology 60, 9:1299-1309.

Ogden AR, Pinhasi R, and White WJ. 2007. Gross enamel hypoplasia in molars from subadults in a 16th-18th century London graveyard. American Journal of Physical Anthropology 133, 3:957-966.

Ogden AR, Pinhasi R, and White WJ. 2008. Nothing new under the heavens: MIH in the past? European Archives of Paediatric Dentistry 9, 4:166-171.

Oliver K, Messer LB, Manton DJ, Kan K, Ng F, Olsen C, Sheahan J, Silva M, and Chawla N. 2013. Distribution and severity of molar hypomineralisation: trial of a new severity index. International Journal of Paediatric Dentistry.

Ortner DJ. 2003. Identification of Pathological Conditions in Human Skeletal Remains: Elsevier Science.

Oyedele TA, Folayan MO, Adekoya-Sofowora CA, Oziegbe EO, and Esan TA. 2015. Prevalence, pattern and severity of molar incisor hypomineralisation in 8- to 10-year-old school children in Ile-Ife, Nigeria. European Journal of Paediatric Dentistry 16, 3:277282. 
Petrou MA, Giraki M, Bissar AR, Wempe C, Schafer M, Schiffner U, Beikler T, Schulte AG, and Splieth $\mathrm{CH}$. 2015. Severity of MIH findings at tooth surface level among German school children. European Archives of Paediatric Dentistry 16, 3:271-276.

Powers N. 2012. Human osteology method statement MOLA. 64 p.

R Core Team. 2018. R: A language and environment for statistical computing. R Foundation for Statistical Computing, Vienna, Austria. URL https://www.R-project.org/

Rouas P. 2012. L' hypominéralisation molaires-incisives. In: Beauval C, editor. Rapport d'opération de fouilles archéologiques : Sains-en-Gohelle 227 rue Lamartine. p 315-316.

Ruch JV. 2001. Chapitre 1. Developpement dentaire normal. In: Piette E, and Goldberg M, editors. La dent normale et pathologique: De Boeck Université. p 242.

Schneider PM, and Silva M. 2018. Endemic Molar Incisor Hypomineralization: a pandemic problem that requires monitoring by the entire Health Care community. Current Osteoporosis Reports 16, 3:283-288.

Schwendicke F, Elhennawy K, Reda S, Bekes K, Manton DJ, and Krois J. 2018. Global burden of molar incisor hypomineralization. Journal of Dentistry 68:10-18.

Serna C, Vicente A, Finke C, and Ortiz AJ. 2016. Drugs related to the etiology of molar incisor hypomineralization: A systematic review. Journal of the American Dental Association 147, 2:120-130.

Silva MJ, Scurrah KJ, Craig JM, Manton DJ, and Kilpatrick N. 2016. Etiology of molar incisor hypomineralization - A systematic review. Community Dentistry and Oral Epidemiology 44, 4:342-353.

Smith FC. 1916. Mottled Enamel and Brown Stain: A Condition Affecting the Teeth in Certain Localities. Public Health Reports 31, 42:2915-2918.

Stermer EM, Risnes S, and Fischer PM. 1996. Trace element analysis of blackish staining on the crowns of human archaeological teeth. European Journal of Oral Sciences 104, $3: 253-261$.

Stipisic A, Versic-Bratincevic M, Knezovic Z, and Sutlovic D. 2014. Metal content in medieval skeletal remains from Southern Croatia. Journal of Archaeological Science 46:393-400.

Stránská P, Velemínský P, and Poláček L. 2015. The prevalence and distribution of dental caries in four early medieval non-adult populations of different socioeconomic status from Central Europe. Archives of Oral Biology 60, 1:62-76.

Suckling GW. 1989. Developmental defects of enamel--historical and present-day perspectives of their pathogenesis. Advances in Dental Research 3, 2:87-94.

Suga S. 1989. Enamel hypomineralization viewed from the pattern of progressive mineralization of human and monkey developing enamel. Advances in Dental Research 3, 2:188-198.

Tourino LF, Correa-Faria P, Ferreira RC, Bendo CB, Zarzar PM, and Vale MP. 2016. Association between Molar Incisor Hypomineralization in Schoolchildren and Both Prenatal and Postnatal Factors: A Population-Based Study. PloS One 11, 6:e0156332.

Turner-Walker G. 2007. The Chemical and Microbial Degradation of Bones and Teeth. In: Mays RPaS, editor. Advances in Human Palaeopathology: John Wiley \& Sons, Ltd, Chichester, UK. . p p. 11-15. 
Vieira AR, and Kup E. 2016. On the Etiology of Molar-Incisor Hypomineralization. Caries Research 50, 2:166-169.

Vodanovic M, Brkic H, Slaus M, and Demo Z. 2005. The frequency and distribution of caries in the mediaeval population of Bijelo Brdo in Croatia (10th-11th century). Archives of Oral Biology 50, 7:669-680.

Walter BS, DeWitte SN, and Redfern RC. 2015. Sex differentials in caries frequencies in Medieval London. Archives of Oral Biology 63:32-39.

Watts A, and Addy M. 2001. Tooth discolouration and staining: a review of the literature. British Dental Journal 190, 6:309-316.

Weerheijm KL. 2003. Molar incisor hypomineralisation (MIH). European Journal of Paediatric Dentistry 4, 3:114-120.

Weerheijm KL, Duggal M, Mejàre I, Papagiannoulis L, Koch G, Martens LC, and Hallonsten AL. 2003. Judgement criteria for molar incisor hypomineralisation (MIH) in epidemiologic studies: a summary of the European meeting on MIH held in Athens, 2003. European Journal of Paediatric Dentistry 4, 3:110-113.

Weerheijm KL, Jalevik B, and Alaluusua S. 2001. Molar-incisor hypomineralisation. Caries Research 35, 5:390-391.

Whatling R, and Fearne JM. 2008. Molar incisor hypomineralization: a study of aetiological factors in a group of UK children. International Journal of Paediatric Dentistry 18, 3:155-162.

Wogelius P, Haubek D, Nechifor A, Norgaard M, Tvedebrink T, and Poulsen S. 2010. Association between use of asthma drugs and prevalence of demarcated opacities in permanent first molars in 6-to-8-year-old Danish children. Community Dentistry and Oral Epidemiology 38, 2:145-151.

Zimmermann ER. 1954. Fluoride and nonfluoride enamel opacities. Public Health Reports 69, 11:1115-1120. 
Fig. 1. Photographs of data types recording. (a) Hypoplasia on 36 from LSS85 541, (b) carious lesion on 46 from LSS85 1069, (c) ante-mortem loss of 46 from LSS85 1378, (d) yellow diffuse discoloration on 46 from LSS85 1371, (e) yellow demarcated discoloration on 16 from LSS85 1338, (f) brown demarcated discoloration on 26 from LSS85 1487.

Fig. 2. Photographs of data types recording. a. Lesion color (white, yellow, brown); b. Coronal location (occlusal third / median third / cervical third) and surface affected (buccal, lingual, occlusal, mesial, distal).

Fig. 3. Distributions and characteristics of discolorations among 6 selected individuals by Fleiss' kappa (LSS85 1338, 852, 684, 1322, 1487 and 1197) Wh, white; Ye, yellow; Br, brown; Oc, occlusal; $\mathrm{Bu}$, buccal; Li, lingual; OcLi, Occluso-lingual; OcBu, occluso-buccal; $1 / 3 \mathrm{Co}$, coronal third; $1 / 3$, median third; $1 / 3$, cervical third; $1 / 3 \mathrm{CoMe}$, coronal and median third.

Fig. 4. Photographs of teeth stained by taphonomic processes with well demarcated discolorations (a) individual MIN86 $10491\left(11^{\text {th }}-15^{\text {th }}\right.$ century, Museum of London, UK), (b) and (c) individual GYE92 $10699\left(11^{\text {th }}-16^{\text {th }}\right.$ century, Museum of London, UK).

Fig. 5. Photographs of differential diagnoses of MIH (a) enamel hypoplasia on 46 from individual FAO90 $2101\left(18^{\text {th }}-19^{\text {th }}\right.$ century, St Brides Lower Churchyard London, UK), (b) Mulberry molar $n^{\circ} 26$ from individual REW92 67 (19 ${ }^{\text {th }}$ century, Cross Bones, London, UK), (c) white spot on 16 from a current individual (CHU de Bordeaux, Pôle Odontologie et santé buccale, Pellegrin, France), (d) white spot with extrinsic discolorations on 46 from individual SeG $571\left(10^{\text {th }}-13^{\text {th }}\right.$ century Sains-en-Gohelle, France), (e-g) individual with enamel hypoplasia, enamel and dentine hypomineralisation (e-f), a narrow maxilla and severe periodontal lesions of first permanent mandibular molar (f) suggesting Rickets (individual OCUOO 230, $18^{\text {th }}-19^{\text {th }}$ century, Chelsea Old Church, London, UK). 

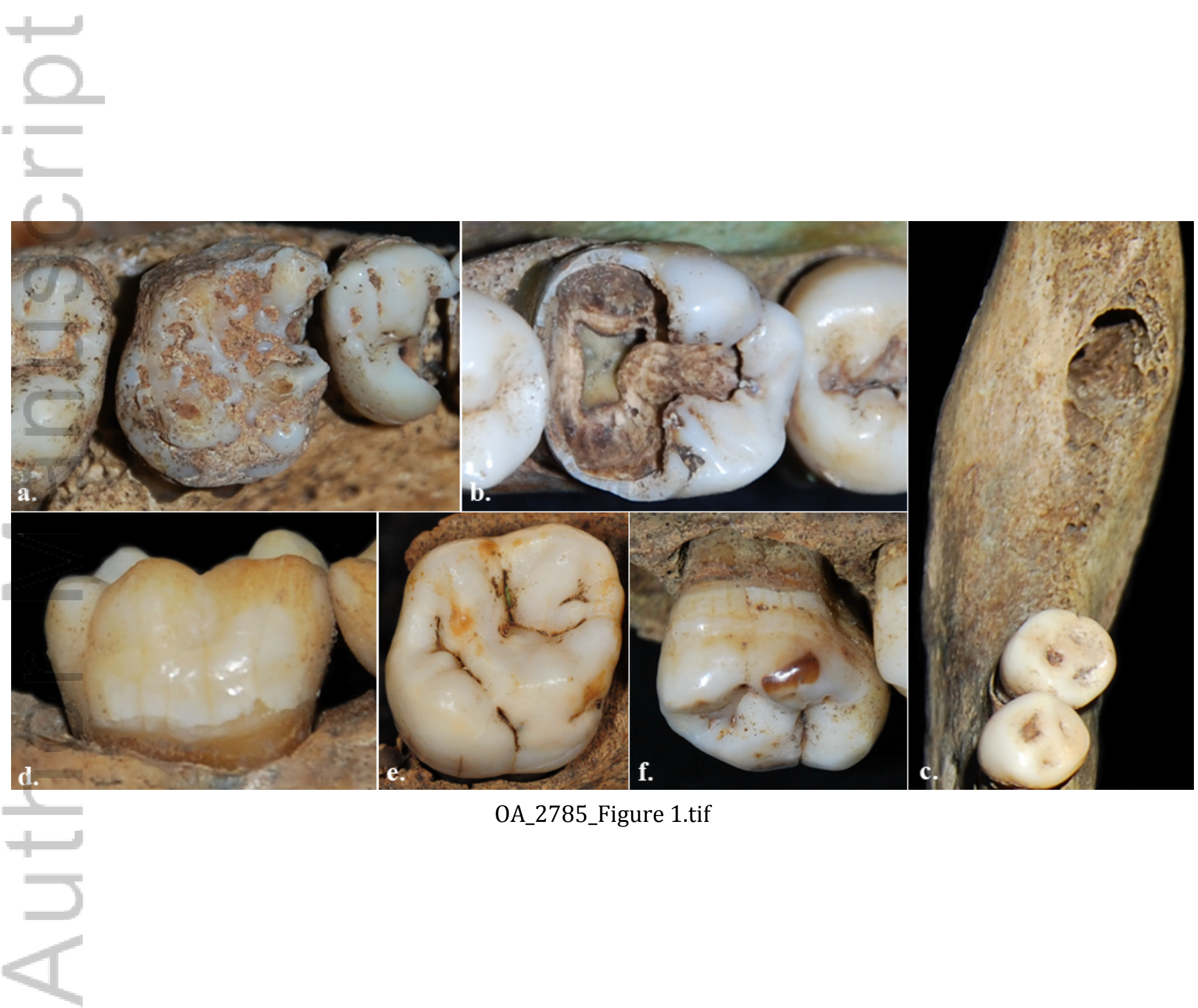

OA_2785_Figure 1.tif

This article is protected by copyright. All rights reserved. 

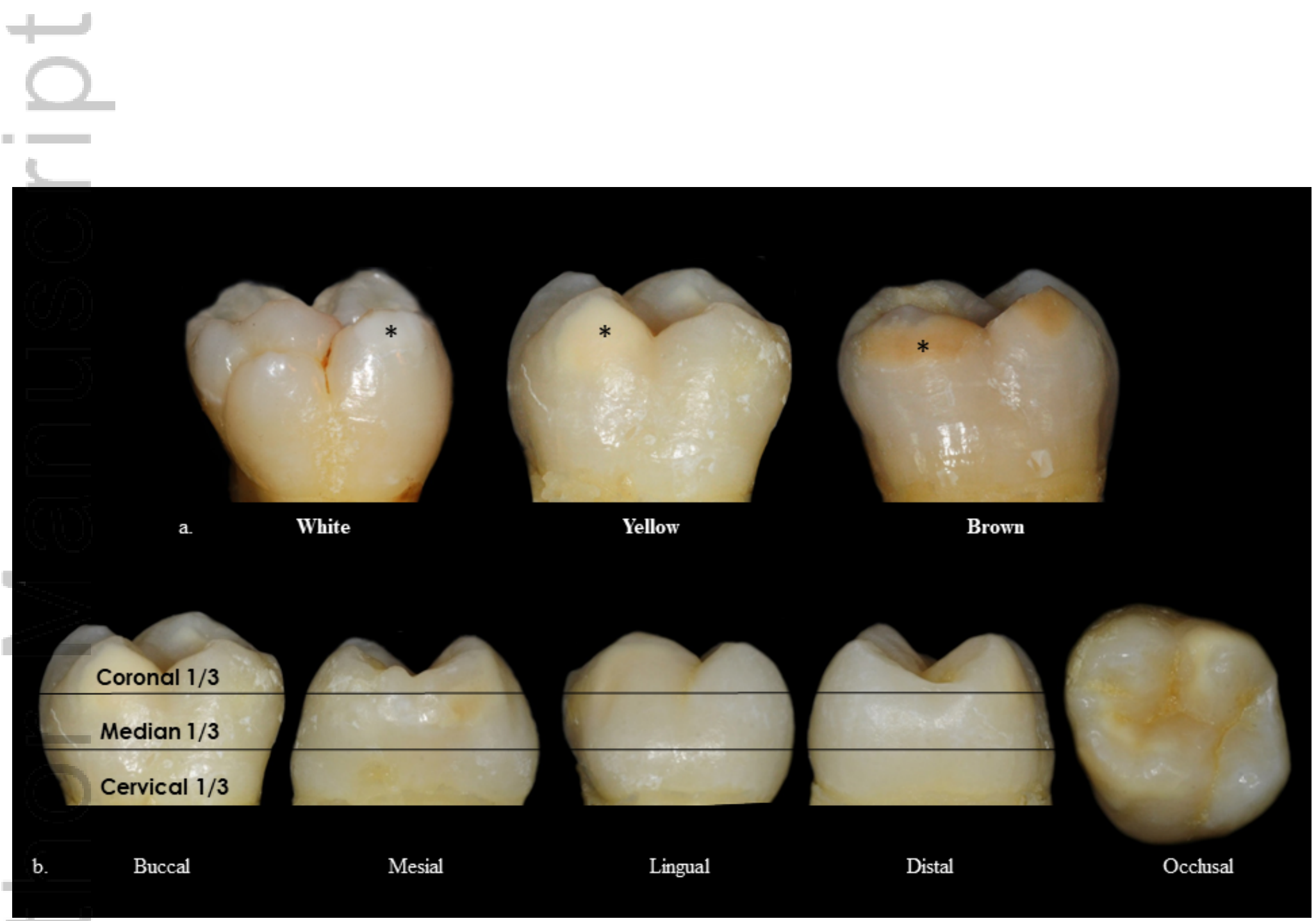

OA_2785_Figure 2.tif

This article is protected by copyright. All rights reserved. 
$\mathrm{n}$

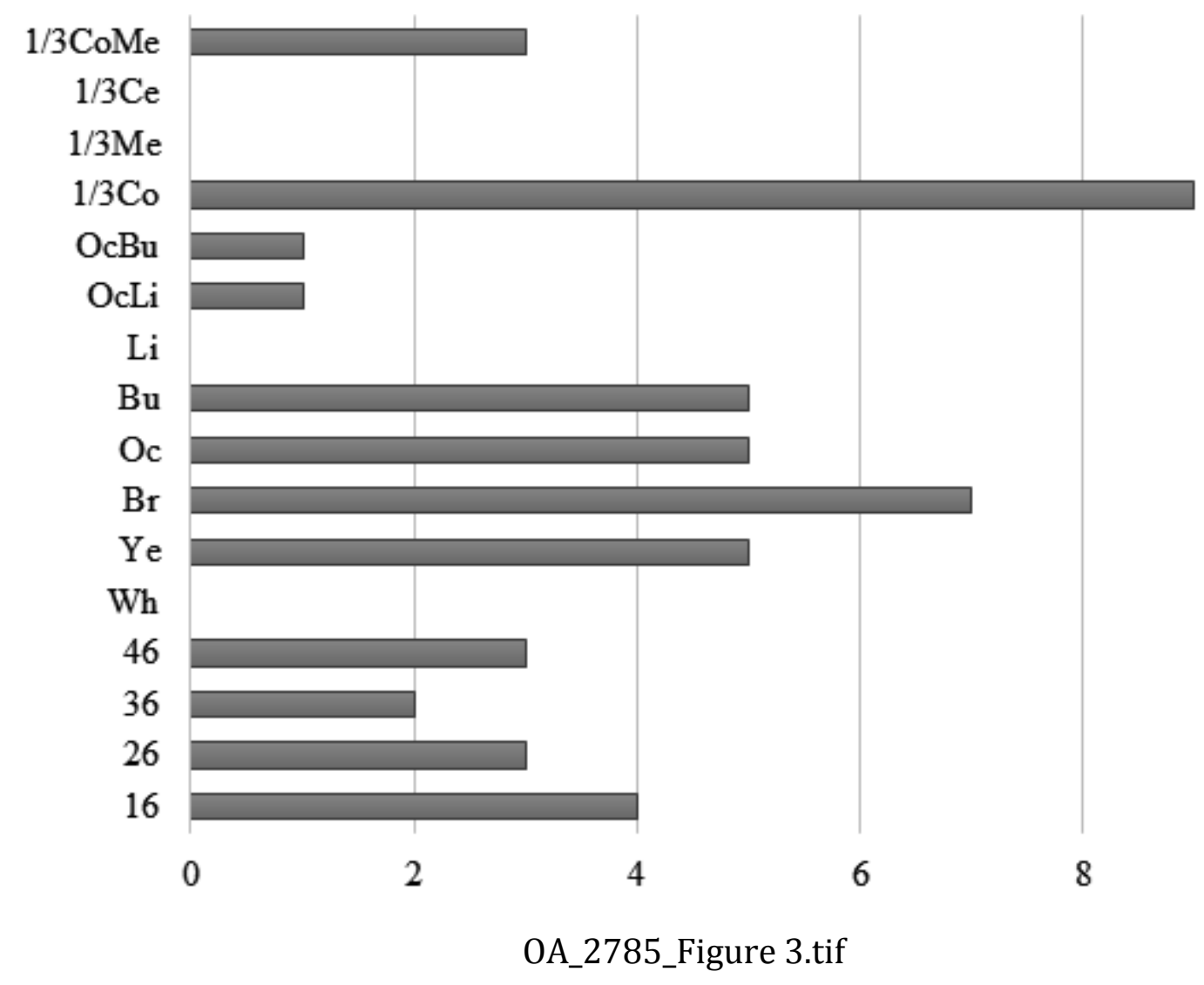

This article is protected by copyright. All rights reserved. 
a.
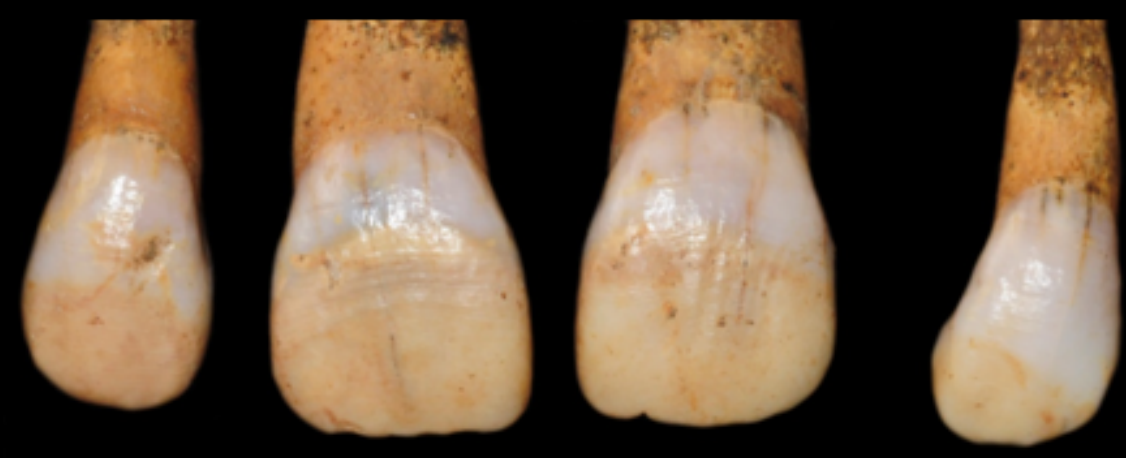

b.

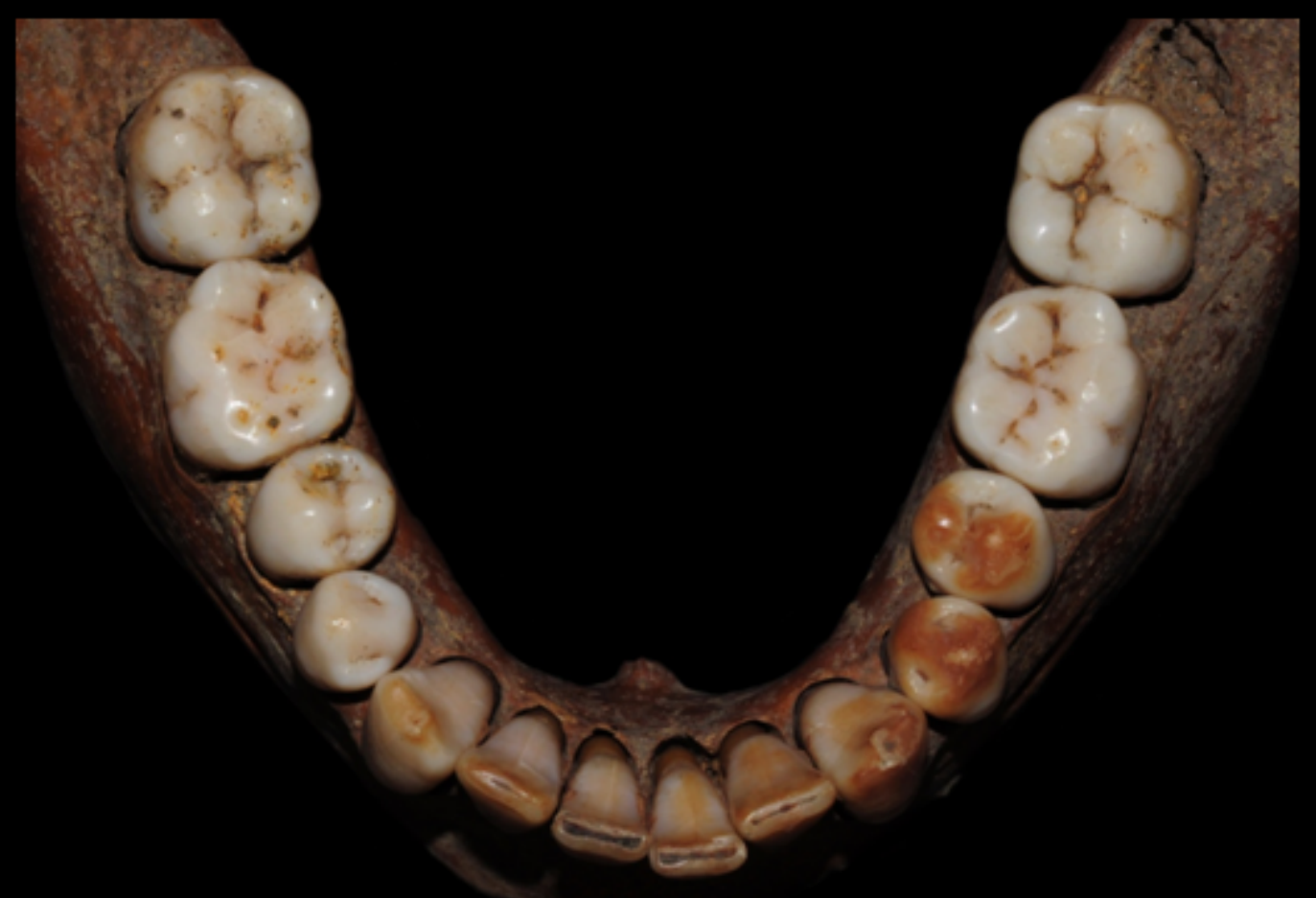

c.

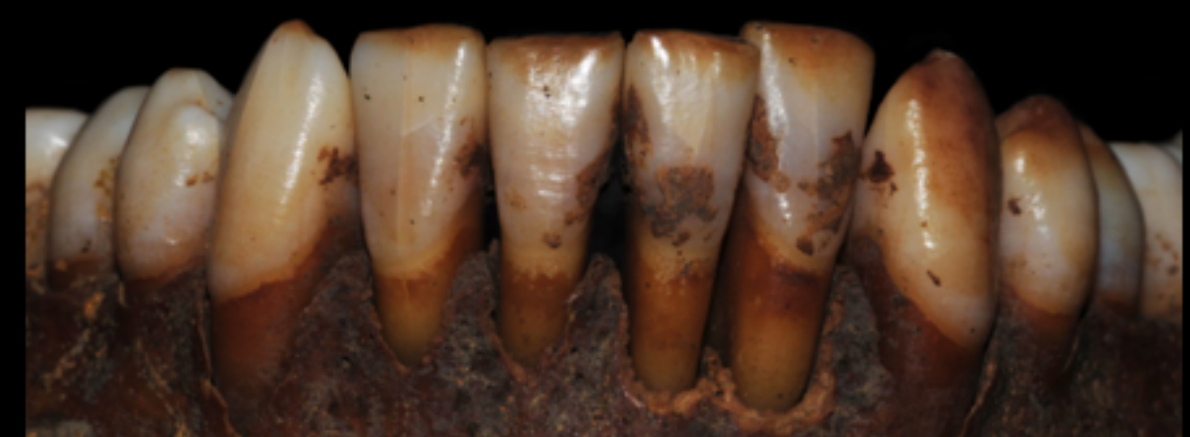

OA_2785_Figure 4.tif

This article is protected by copyright. All rights reserved. 


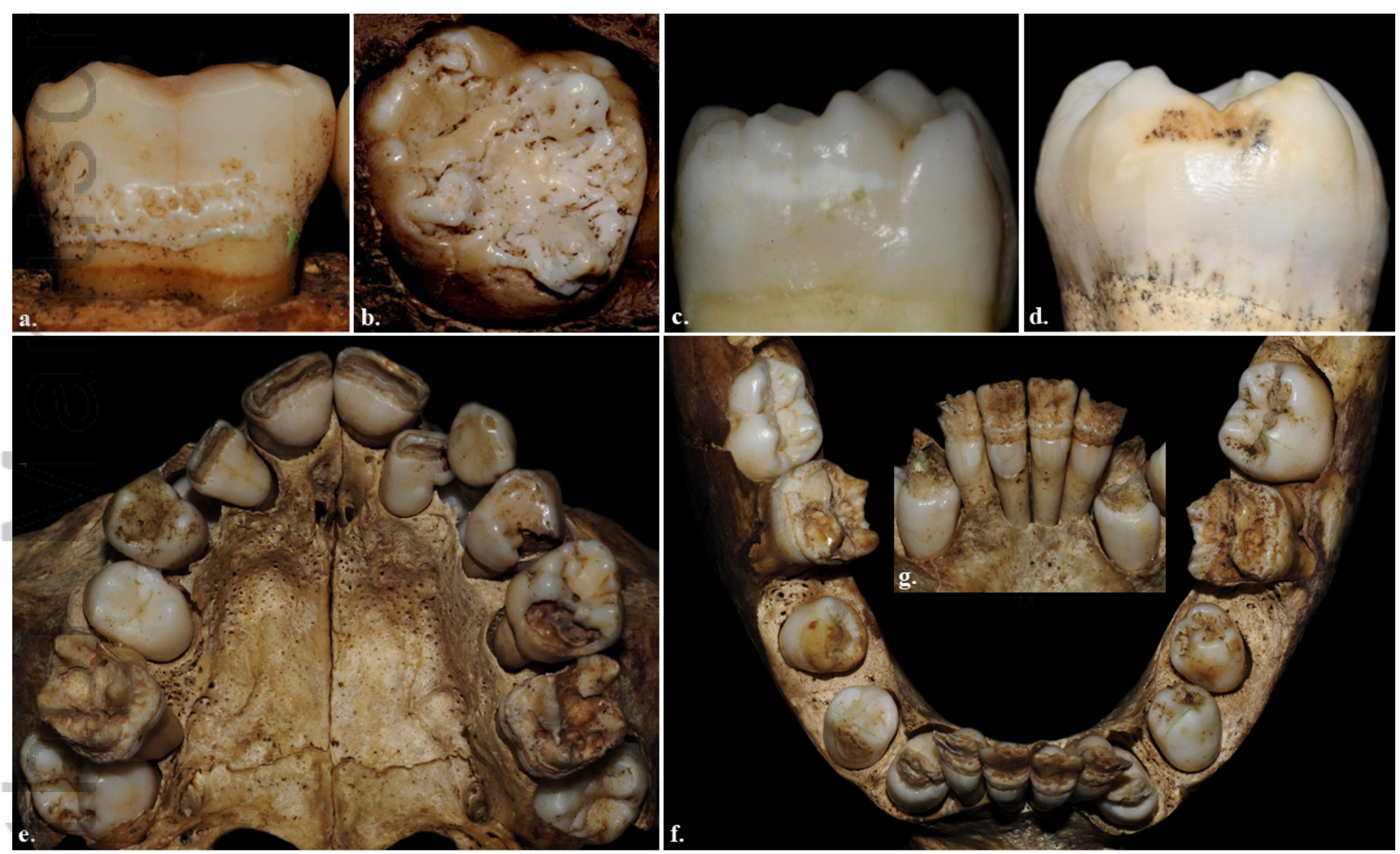

OA_2785_Figure 5.tif 


\section{University Library}

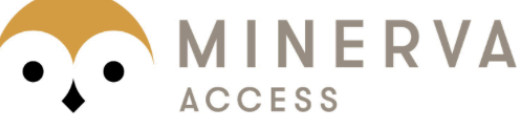

A gateway to Melbourne's research publications

Minerva Access is the Institutional Repository of The University of Melbourne

Author/s:

Garot, E;Couture-Veschambre, C;Manton, DJ;Bekvalac, J;Rouas, P

Title:

Differential diagnoses of enamel hypomineralisation in an archaeological context: A postmedieval skeletal collection reassessment

Date:

2019-06-28

Citation:

Garot, E., Couture-Veschambre, C., Manton, D. J., Bekvalac, J. \& Rouas, P. (2019). Differential diagnoses of enamel hypomineralisation in an archaeological context: A postmedieval skeletal collection reassessment. INTERNATIONAL JOURNAL OF OSTEOARCHAEOLOGY, 29 (5), pp.747-759. https://doi.org/10.1002/oa.2785.

Persistent Link:

http://hdl.handle.net/11343/286052 